\title{
Treatment of a Class II Division 2 Patient with Severe Skeletal Discrepancy by Using a Custom Made TPA Proclination Spring
}

\author{
Sergio Paduano ${ }^{1}$, Gianrico Spagnuolo ${ }^{2}$, Giuseppe di Biase ${ }^{3}$ and Iacopo Cioffi ${ }^{2, *}$ \\ ${ }^{I}$ School of Dentistry, University "Magna Graecia” Catanzaro, Italy \\ ${ }^{2}$ Department of Neurosciences and Oral Sciences, University of Naples Federico II, Naples. Italy \\ ${ }^{3}$ Laboratorio ortodontico Giuseppe di Biase, Pomigliano d'Arco, Naples. Italy
}

\begin{abstract}
This case report describes the orthodontic treatment of a boy, aged 15.3 years, with permanent dentition, mesofacial typology, affected with a severe sagittal skeletal Class II division 2 malocclusion, due to a mandibular retrusion. His chief compliant was the position of the maxillary incisors, displaced too palatally, and an impaired facial profile. Herbst and multibracket straightwire fixed appliances, together with a custom made modified transpalatal arch (i.e. TPA proclination spring), were used to correct the sagittal discrepancy and to improve the attractiveness of the impaired facial profile.
\end{abstract}

Keywords: Class II division 2, Skeletal sagittal discrepancy, functional therapy.

\section{INTRODUCTION}

Frequently patients with skeletal Class II present mandibular retrusion with the upper maxilla normally positioned or retruded. As a consequence of this, the correction of dental and jaw sagittal relationships should be achieved by advancing the lower jaw [1].

It has been suggested that functional appliances that posture the mandible forward (i.e. bite jumping appliances) could be used to obtain a sagittal increase of the lower jaw [2]. Furthermore, no compliance appliances, such as the Herbst appliance, have been shown to capably treat class II division 2 malocclusions [3]. Finally, it has been reported that unlocking the bite in class II division 2 individuals, by correcting incisor torque, enhances the forward growth of the mandible [4].

According to these principles we present the treatment of a 15.3 year-old patient affected with a sagittal skeletal and dental Class II division 2 malocclusion with a severe overbite and severe palatal inclination of the upper central incisors (Fig. 1, Fig. 2). The convex profile aesthetically improved with the mandibular advancement by means of the Fraenkel manouvre [5] (Fig. 3), although the use of this procedure in class II division 2 individuals might be tricky for the final assessment $[5,6]$. Temporomandibular joint (TMJ) disorders were not present according to Research Diagnostic Criteria for temporomandibular disorders (RDC/TMD) [7]. Nonetheless, the patient reported frequent oral parafuctions, such as clenching, that have been suggested to be related to muscle pain $[8,9]$. Oral mucosa and gingiva conditions were

*Address correspondence to this author at the Department of Neuroscience, University of Naples Federico II, Via Pansini 5, I 80131 Naples, Italy; Tel: 00390817462195; Fax: 00390817462192.

E-mail: iacopo.cioffi@gmail.com good despite a scanty oral hygiene. The cephalometric features are presented in Fig. (4).

The treatment plan included: a) the positioning of a modified transpalatal arch to advance the upper incisors, increasing overjet, and allow a forward posture of the lower jaw with a functional appliance; b) a Herbst appliance to improve the retruded profile [6]; c) upper and lower arch multibracket self-ligating fixed appliance for alignment, levelling and correction of the malocclusion c) post- treatment retention.

\section{CASE PRESENTATION}

\section{Diagnosis and Treatment Plan}

The patient presented this objective problem list:

- Class II division 2 skeletal malocclusion in permanent dentition;

- Severe overbite $(+10 \mathrm{~mm})$ with palatal inclination of central upper incisors;

- Retruded convex profile;

The cephalometric evaluation highlighted a mesofacial typology with a sagittal skeletal relationship of Class II due to mandible retrusion, and a palatal inclination of central upper incisors (Fig. 4).

The treatment plan included the correction of the inclination of central incisors with an upper fixed modified transpalatal arch (TPA proclination spring, Fig. 5), with superelastic NiTi coil springs connected to stainless steel push rods extended on the first upper central incisors. The appliance was fixed on reinforced molar bands (Rollo bands, American Orthodontics, Sheboygan, US) (Fig. 6, 7).

According to the current evidence [1], the correction of Class II and overjet would be performed mostly by functional 

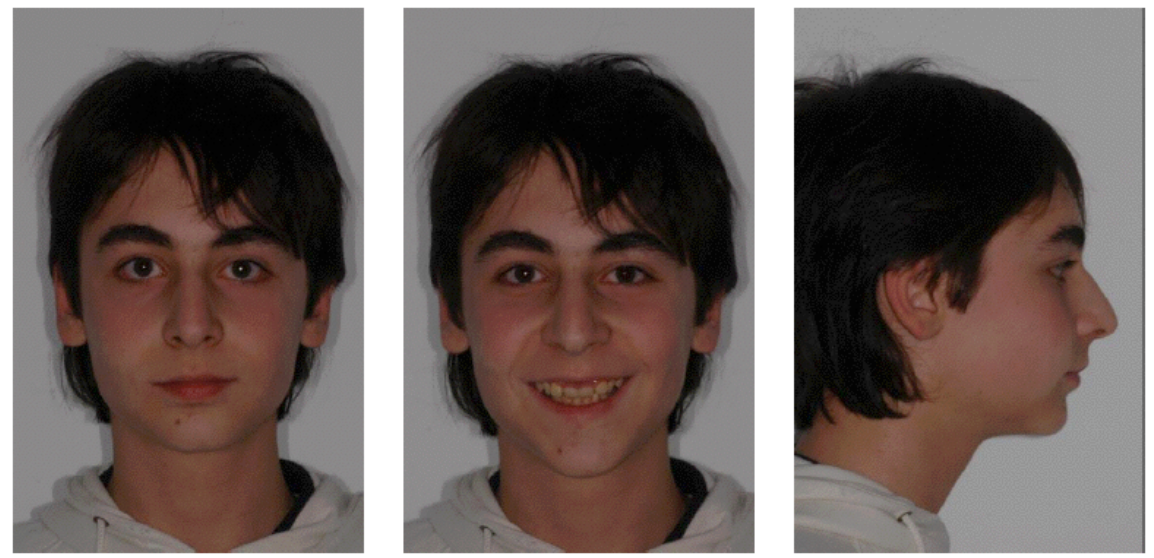

Fig. (1). Extra oral photographs before treatment. Frontal view: no evident asymmetry with good head posture. Upper dental midline is aligned with the facial one. Lateral view: evident mandible retrusion. No labial incompetence was present.
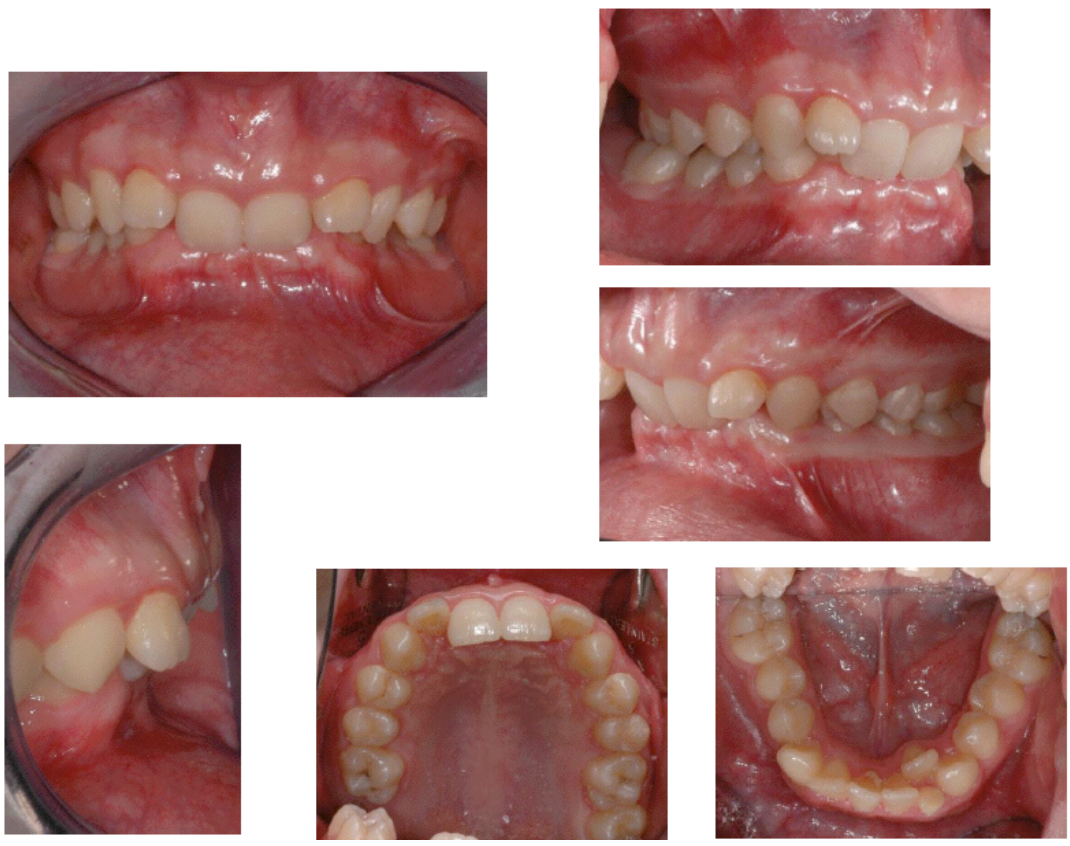

Fig. (2). Intraoral photographs before treatment. No lateral or anterior shifts of the mandible were present. Severe Class II division 2 occlusal relationship with a large ovb $(+10 \mathrm{~mm})$. Good amount of adherent gingival.
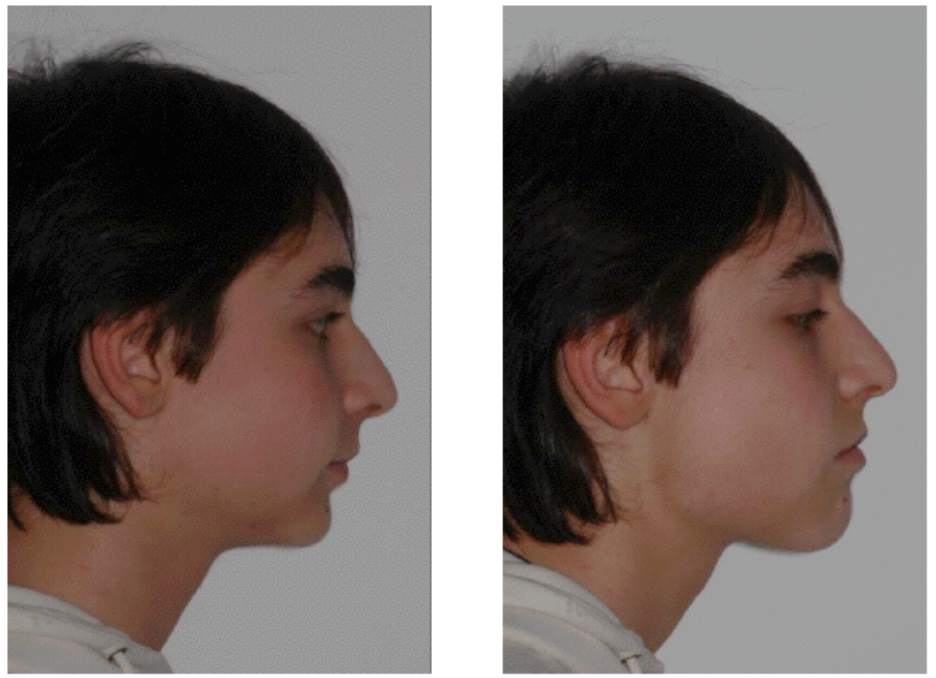

Fig. (3). Frankel manoeuvre. The convex profile improved with the Fraenkel manoeuvre. 

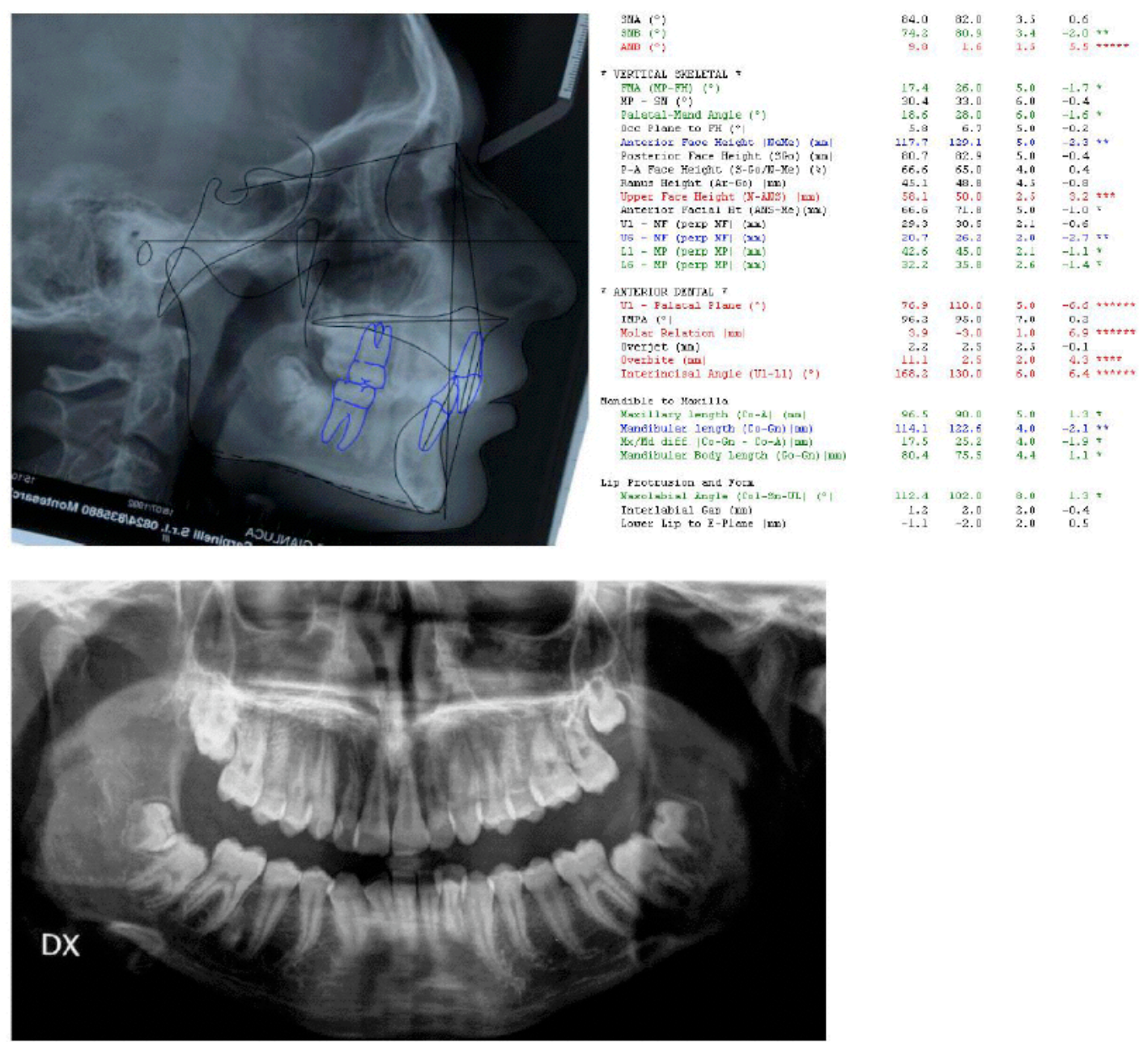

Fig. (4). Cephalometric values and panoramic radiograph at the start of treatment. From left to right: value measured, average value from the population norm, standard deviation of the average value from the population norm, difference from the extreme value of the population norm. Red: values above the norm, Green: values below the norm, Black: values within the norm.

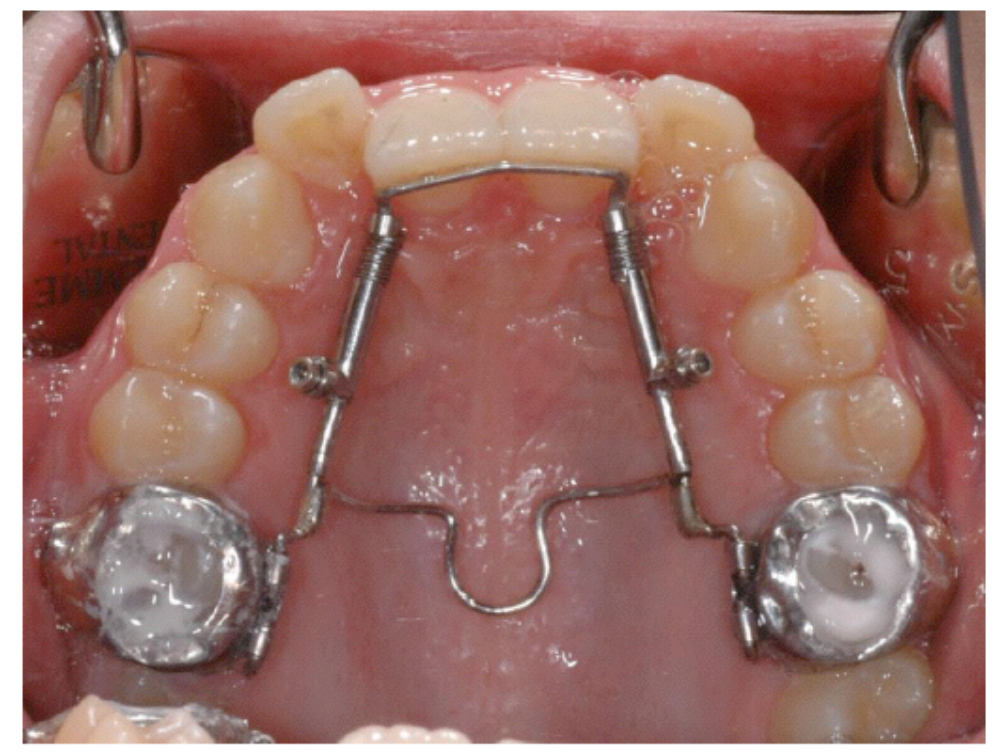

Fig. (5). TPA proclination spring. Modified transpalatal arch (stainless steel 0.036 ") with NiTi superalastic coil springs and push rods extended on the upper central incisors. The activation is performed by locking the soldered screws with a custom-made screwdriver. 

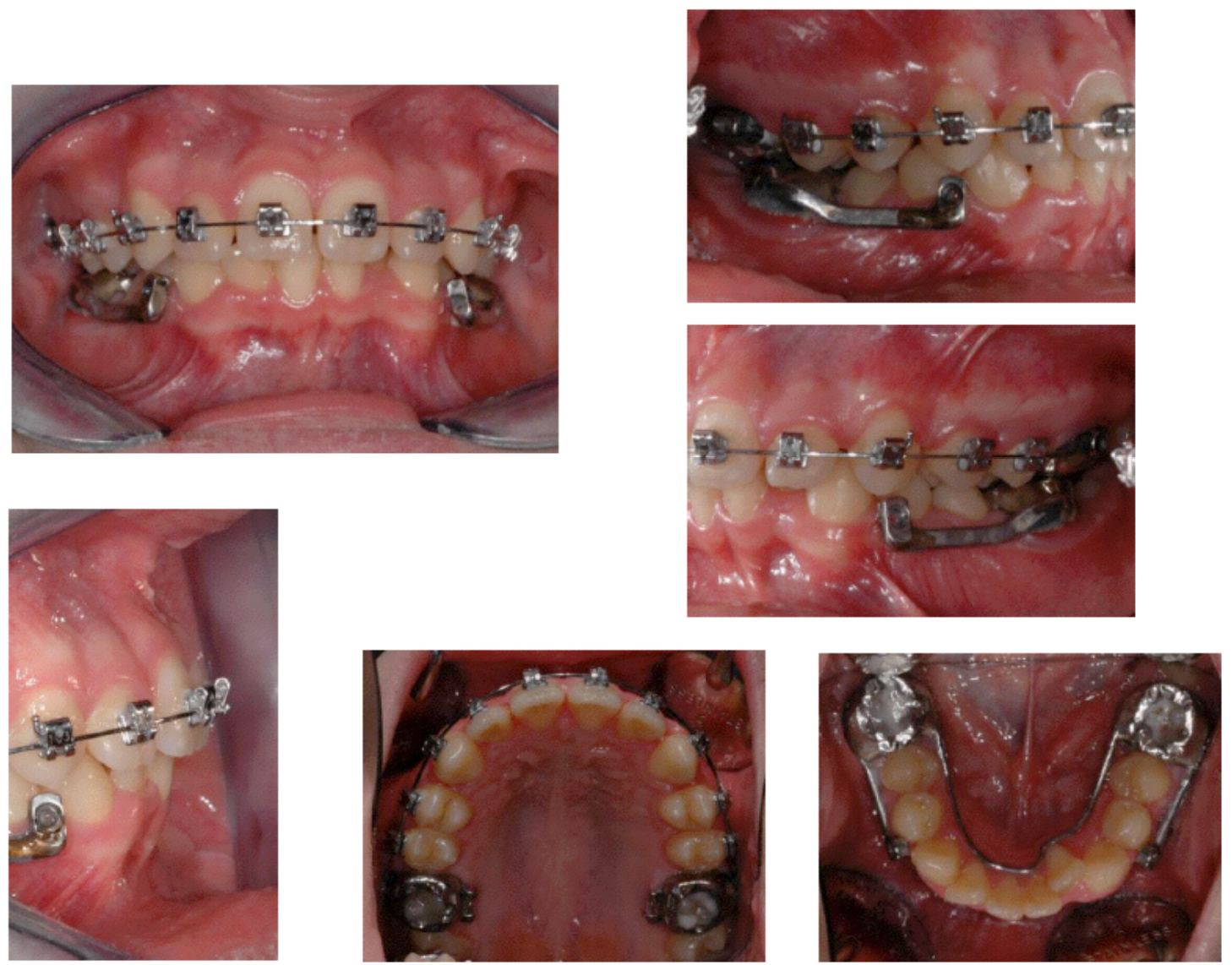

Fig. (6). Herbst miniscope in place.
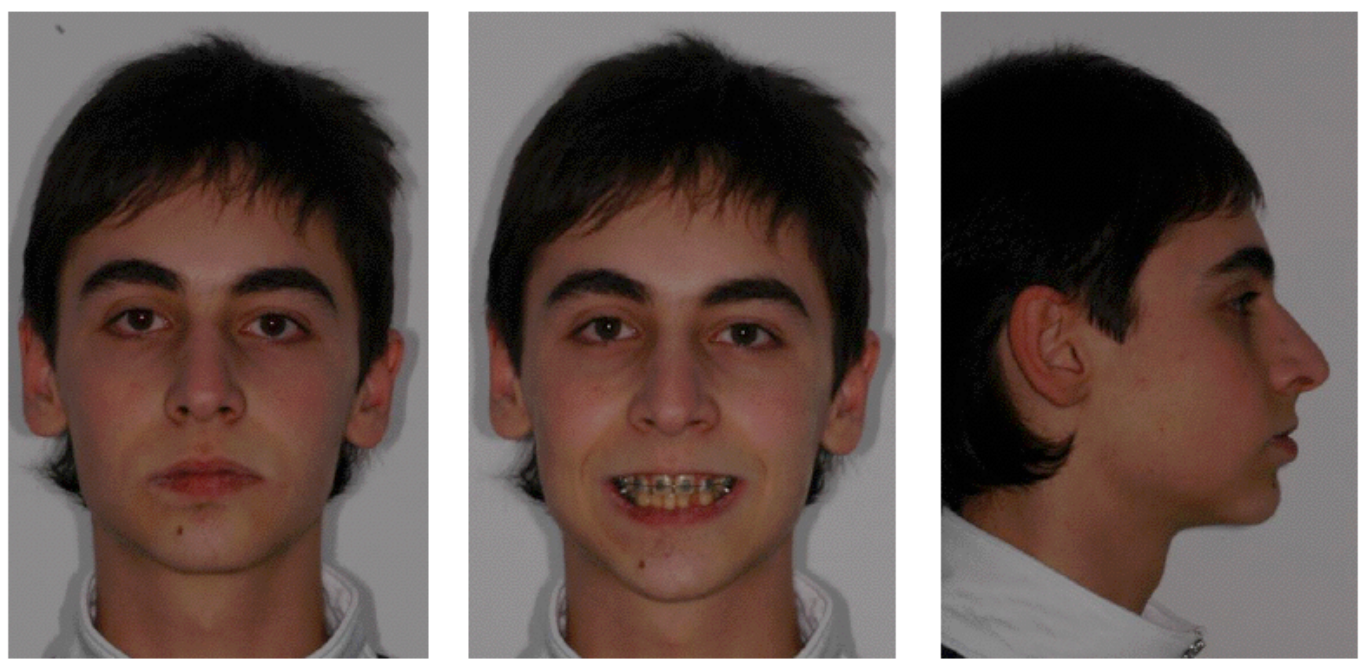

Fig. (7). Extraoral photographs following Herbst appliance.

appliances. In this case, we used a fixed no compliance functional appliance (Herbst miniscope, American Orthodontics, Sheboygan, US) due to the well-known scarce cooperation of teenager patients. In order to increase the orthopaedic effects of the device, the appliance was designed to obtain a maximum anchorage of the upper and lower arches. The fixed self-ligating multibracket appliance was placed to solve the dental crowding, obtain the intrusion of upper and lower incisors to correct the overbite, and reduce the chairside time [10] (Fig. 8).

\section{Treatment Sequence}

- Correction of first upper molar rotation with transpalatal arch;

- Correction of upper incisor torque by means of a modified transpalatal arch with Ni-Ti coil springs and push rods;

- Pleacement of Herbst appliance to correct skeletal Class II and overjet; 

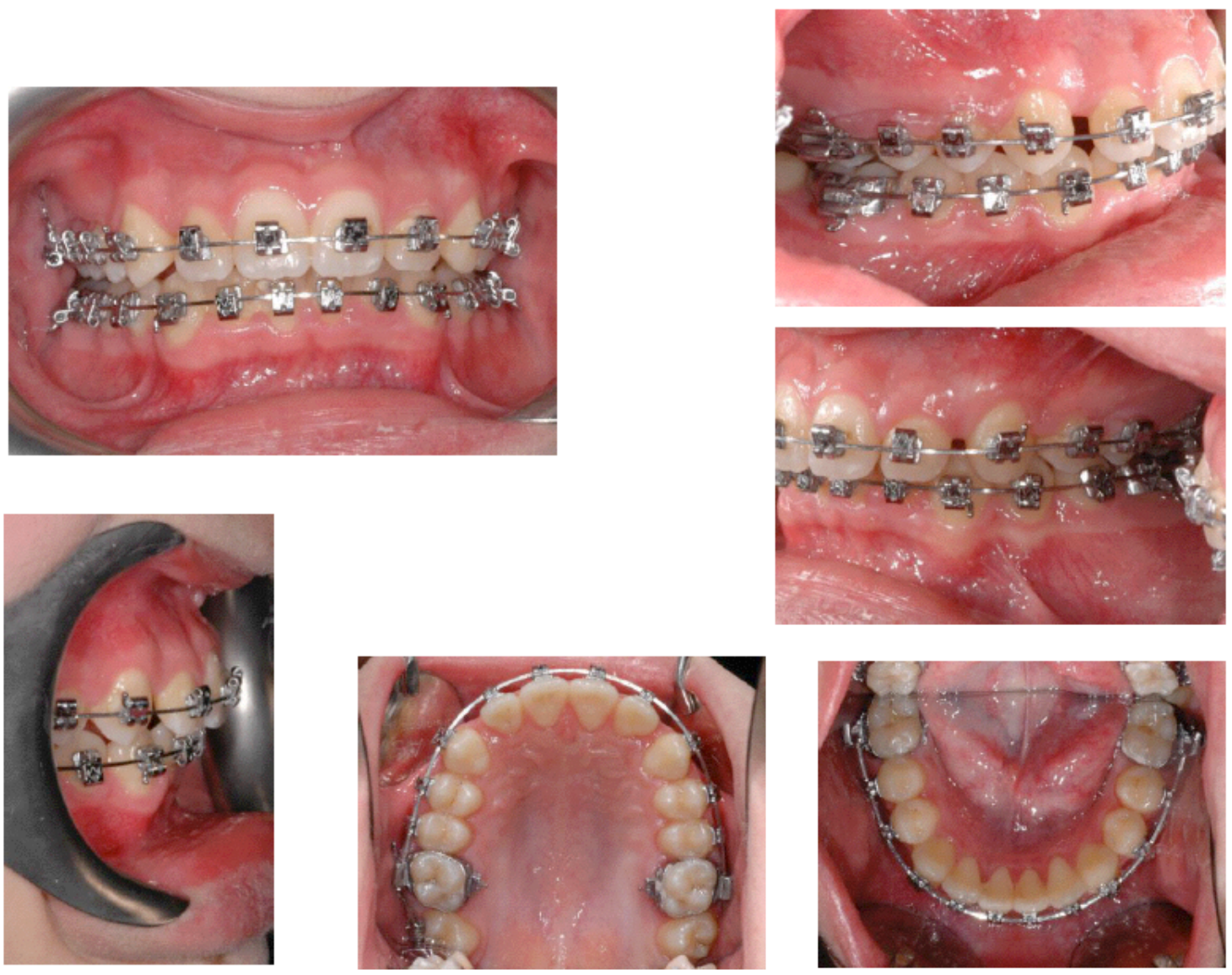

Fig. (8). Intraoral photographs during treatment. 0.019 " $\mathrm{x} 0.025$ " Stailess steel archwires in place.

- $\quad$ Upper and lower fixed straight wire self-ligating multi bracket appliances, with Dr. Roth prescription, slot .022 .

\section{Archwire Selection}

-0.014 HA (heat-activated) Ni-Ti upper and lower alignment archwires (3M Unitek, Monrovia, Ca,US);

$-0.016 \mathrm{HA} \mathrm{Ni-Ti} \mathrm{upper}$ and lower alignment archwires (3M Unitek, Monrovia, Ca,US);

-0.016 AJ Wilcock Australian regular plus (GH wire, Franklin, IN, US) upper and lower alignment archwires with coil open for space opening of the 4.2;

$-0.018 \times 0.025 \mathrm{HA} \mathrm{Ni}-\mathrm{Ti}$ wire upper and lower archwires (3M Unitek, Monrovia, Ca,US);

$-0.019 \times 0.025 \mathrm{SS}$ upper and lower archwires (3M Unitek, Monrovia, $\mathrm{Ca}, \mathrm{US})$.

\section{Mechanics and Treatment Strategies}

- Upper and lower second molars were banded at the first stages of the treatment to level the curve of Spee and increase the mechanics for class II correction.

- Use of HA Ni-Ti archwires to reduce orthodontic forces and improve patient discomfort [11].

- The upper incisors were retracted by a translation arch (0.019x0.025 TMA, Ormco, Orange, Ca, US) with differential anchorage and class two elastics [12].
- Finishing with $0.018 \times 0.025$ multibraded wires $(3 \mathrm{M}$ Unitek, Monrovia, Ca,US) with vertical elastics (1/8" $4 \mathrm{Oz})$.

- Retention with a lower retainer (wildcat round wire 0.0195", DENTSPLY GAC International, Islandia, NY, US) extended from 3.3 to 4.3 .

\section{DISCUSSION}

The major objectives of the treatment were achieved after 31 month of active treatment. The patient was seen approximately every three weeks during the orthodontic treatment. The occlusion and the facial profile improved (Fig. 9, 10). Molar and canine Class I relationship was achieved with overjet and overbite within the norms. The panoramic radiograph showed a good radicular parallelism and no signs of root resorption. The cephalometric analysis showed an improvement of the sagittal intermaxillary relation and a slight counter clockwise rotation of the mandible (Fig. 11, 12). The patient constantly showed a very poor oral hygiene. Hence, even during treatment, gingival inflammations were present. The clinical examination of the masticatory muscles and TMJ did not show any pathological signs or symptoms at completion of treatment.

The results achieved were maintained during the retention period by means of a fixed lingual 33-43 retainer that has not been removed yet. The results achieved were substantially maintained at two year post-treatment control 

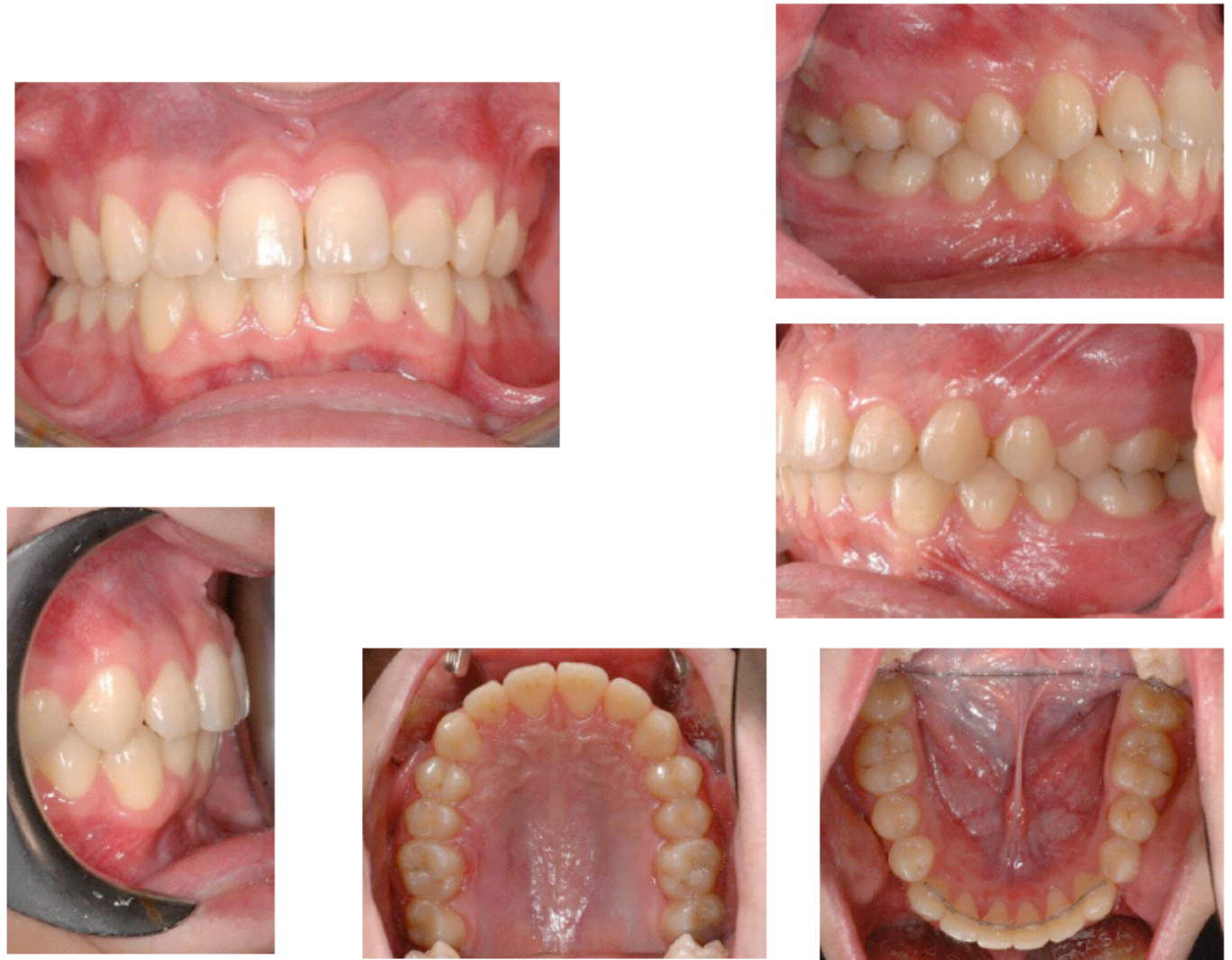

Fig. (9). Intraoral photographs after treatment.
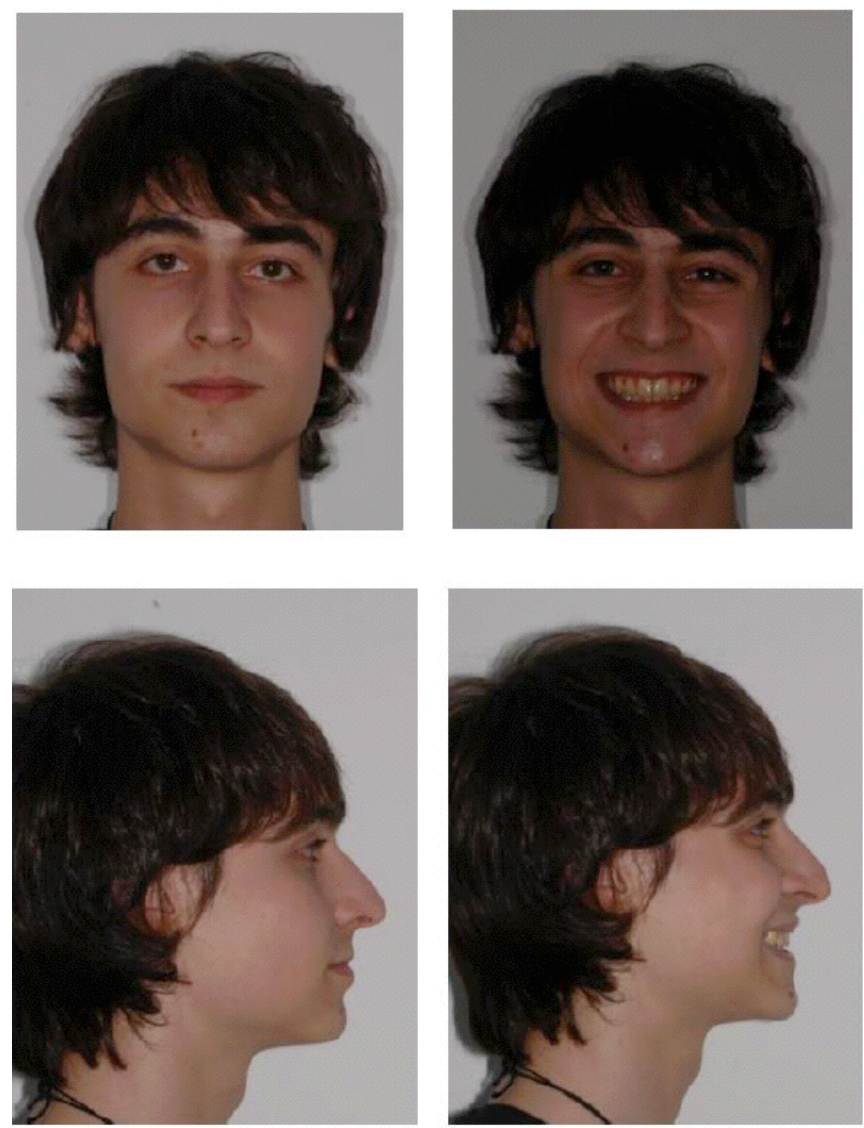

Fig. (10). Extraoral photographs after treatment. 


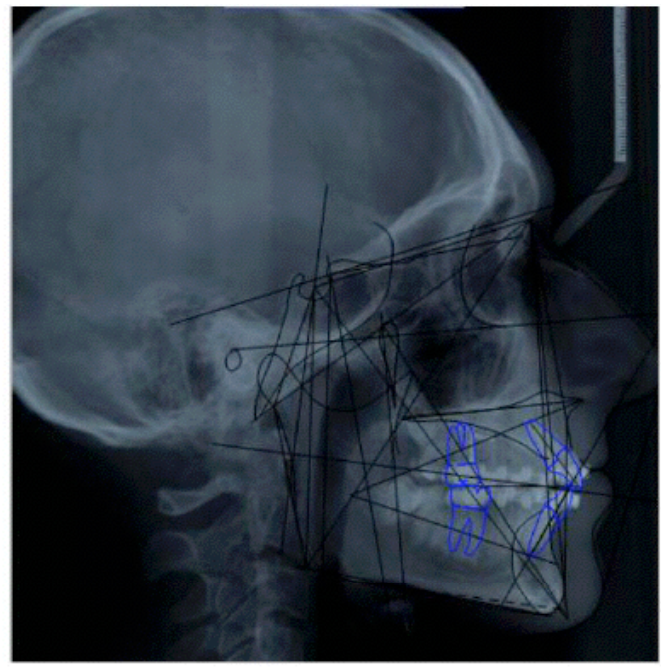

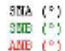

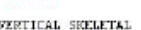

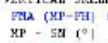

Palecel-Yans Angle $1^{\circ}$ )

occ plane to त्व $\left.l^{\circ}\right)$

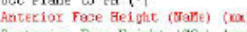

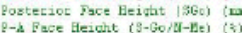

Ravvs Heiaght $\left(a_{2}-C_{0}\right)$ (ala)

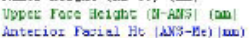

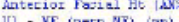

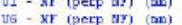

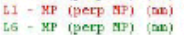

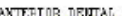

Tr- Paletal Plene $\left.1^{\circ}\right)$

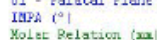

Derecjet (an)

Inemite $\mid$ mat

andible to toxi110

Yaxillary Langth (co-a) (x)

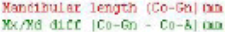

Xancibulax sody tength $\mid 60-G$ an (aw

$\begin{array}{cccc}83.2 & 88.0 & 3.5 & 0.3 \\ 76.5 & 60.9 & 9.4 & -1.3 \\ 6.7 & 1.6 & 1.5 & 3.4 \\ 6 & & & \end{array}$

Proteusion and Fora

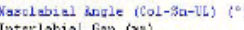

Gap (x)

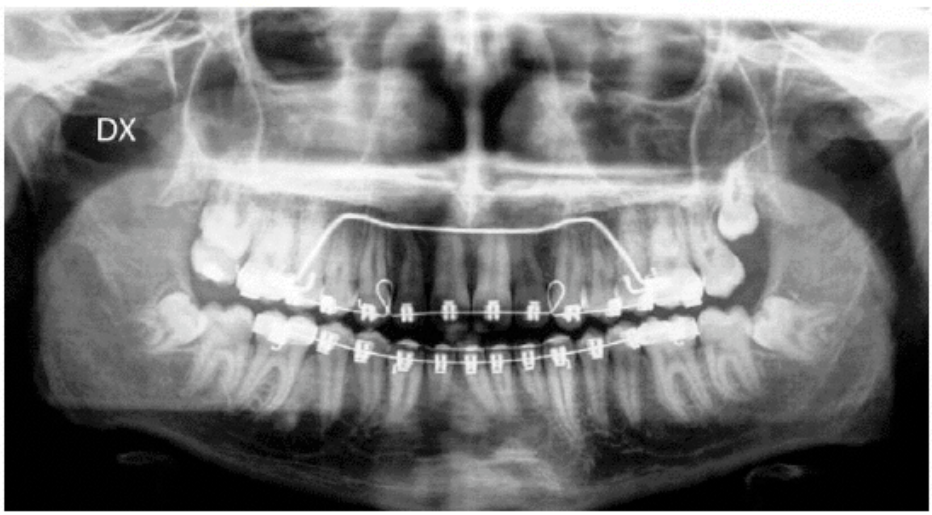

$\begin{array}{llll}14.5 & 26.0 & 5.0 & -2.3 \\ 26.9 & 33.0 & 6.0 & -1.3\end{array}$

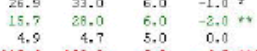

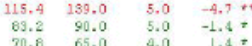

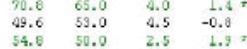

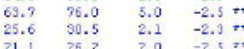

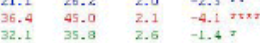

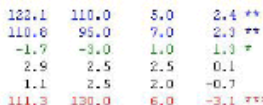

$\begin{array}{rrrr}91.2 & 90.0 & 5.0 & 0.2 \\ 113.4 & 128.3 & 4.0 & -3.720 .7 \\ 22.2 & 28.0 & 4.0 & -1.5 \\ 78.7 & 80.0 & 4.4 & -0.3 \\ 7.9 & & 4.4\end{array}$

$\begin{array}{rrrr}119.9 & 102.0 & 6.0 & 2.2 \% \\ 0.0 & 2.0 & 2.0 & -1.0 \\ -4.5 & -2.0 & 7.0 & -1.0 \\ -4.1 & -7\end{array}$

DX

Fig. (11). Cephalmetric values and panoramic radiograph at the end of treatment, before final debonding. From left to right: value measured, average value from the population norm, standard deviation of the average value from the population norm, difference from the extreme value of the population norm. Red: values above the norm, Green: values below the norm, Black: values within the norm
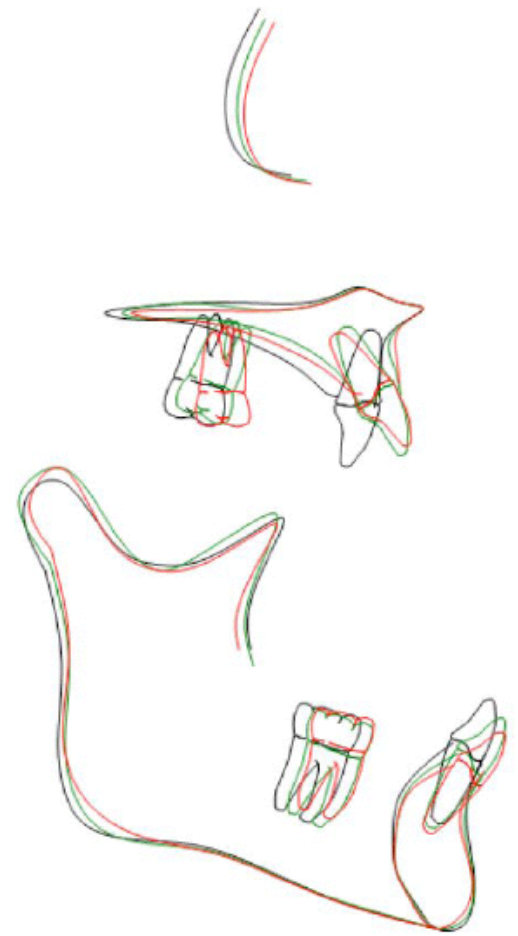

Fig. (12). Tracing superimpositions for upper and lower jaw and dental arches. Black: before treatment. Green: after functional treatment with Herbst appliance, Red: end of treatment. 

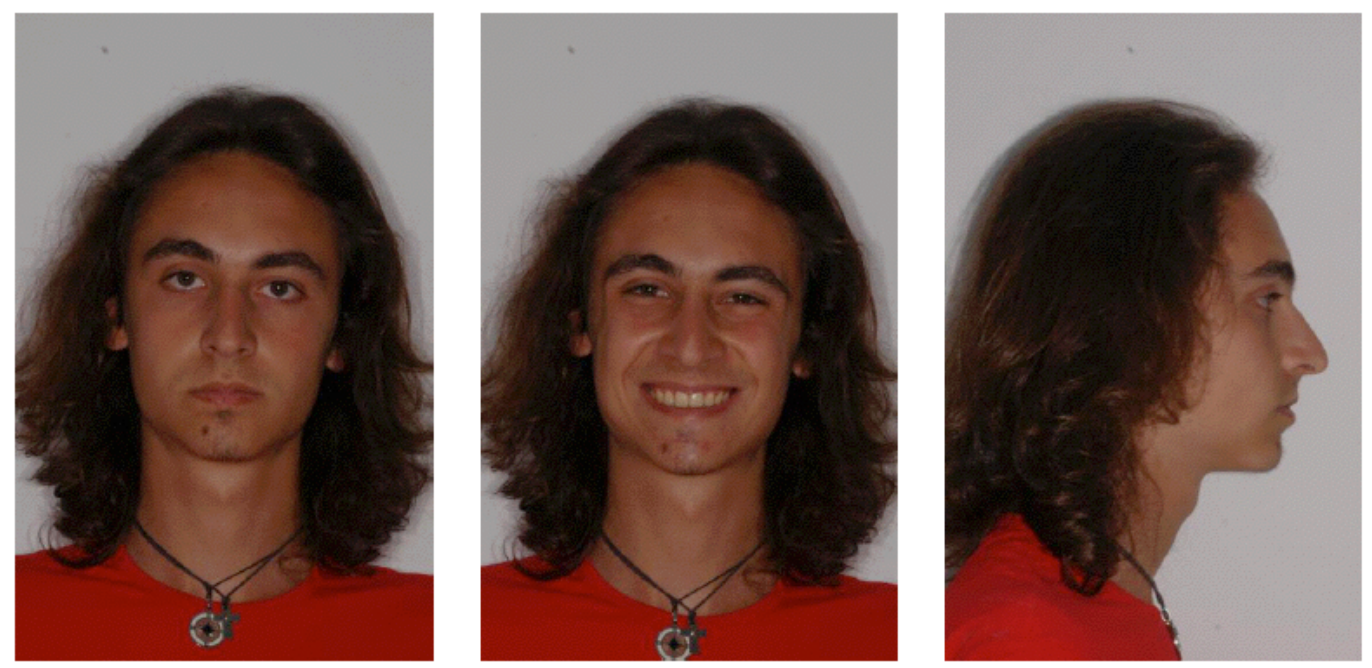

Fig. (13). Extraoral photographs two years after treatment.
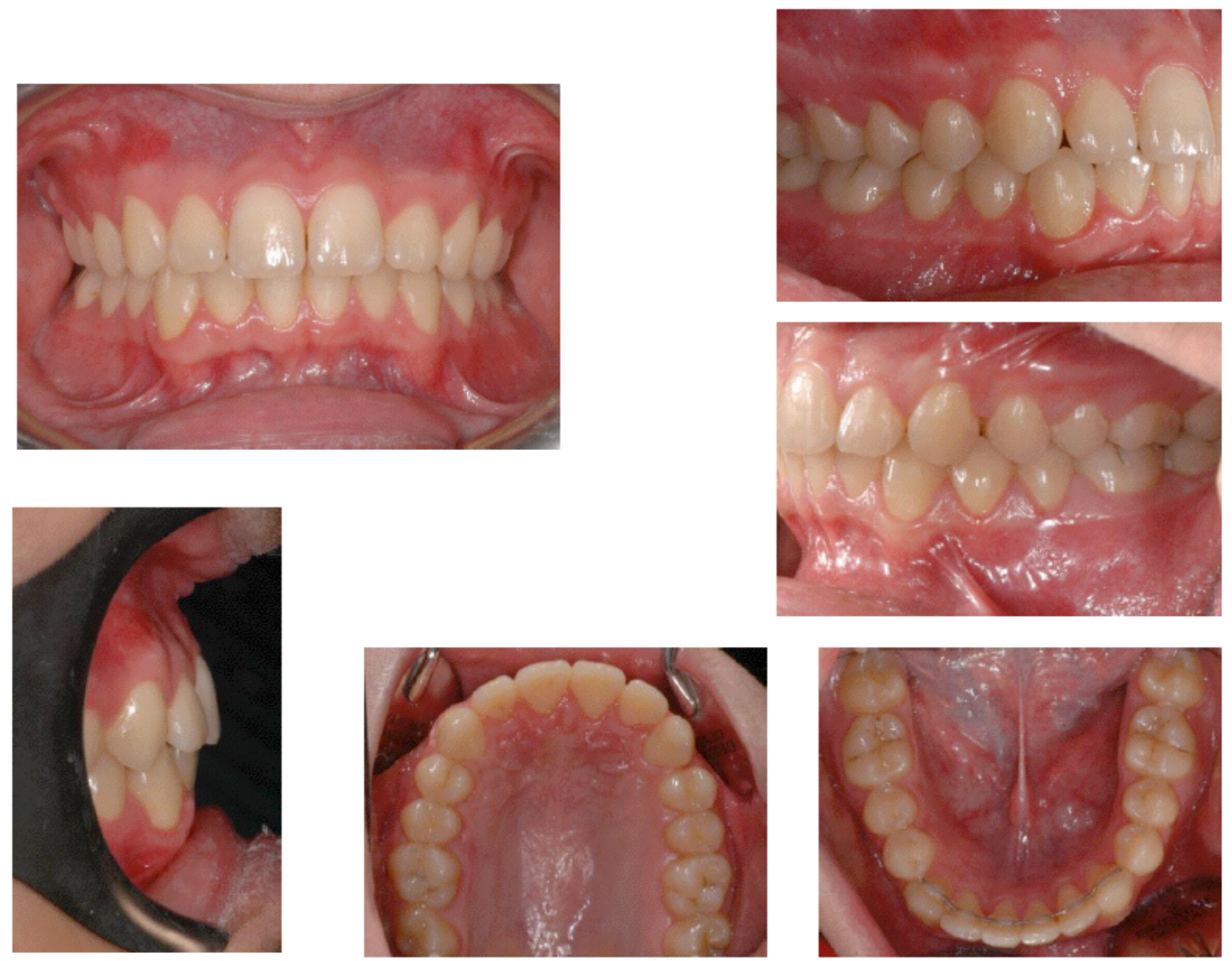

Fig. (14). Intraoral photographs two years after treatment.

(Fig. 13, 14). Occlusal relationship and dental alignment were stable. Cephalometric values did not change in the post-treatment period. Maxillary and mandibular incisor inclination did not show any change overtime. Facial aesthetics improved. That could be the consequence of a gradual adaptation of the soft tissues to dental and bone changes.

\section{CASE SUMMARY}

Case category: Class II division 2 with severe skeletal discrepancy

Name: C.G. born: 07/92 sex: m
Pre-treatment records: age 15 date: 10/07

Classification: skeletal class II division 2

Treatment started: age: 15 date: $11 / 07$

Treatment ended: age 18 date: 07/10

Active treatment time: 31 months

Intermediate records after herbst appliance: age 16.9 date: 04 / 09

Final records: age 17 date: 06/10 
Appliance: herbst miniscope and full straight wire selfligating appliance.

\section{RETAINERS}

a) upper: no retention

b) lower: lingual bonded retainer 33-43

Retention ended:

a) upper: no retention

b) lower: it has not removed yet

Retention time:

a) upper: no retention

b) lower: in place

\section{CONFLICT OF INTEREST}

The authors confirm that this article content has no conflicts of interest.

\section{ACKNOWLEDGEMENTS}

Declared none.

\section{REFERENCES}

[1] Martina R, Cioffi I, Galeotti A, et al. Efficacy of the Sander bitejumping appliance in growing patients with mandibular retrusion: a randomized controlled trial. Orthod Craniofac Res 2013; 16: 11626.

[2] Shen G, Hägg U, Darendeliler M. Skeletal effects of bite jumping therapy on the mandible - removable vs. fixed functional appliances. Orthod Craniofac Res 2005; 8: 2-10.

[3] Vu J, Pancherz H, Schwestka-Polly R, Wiechmann D. Correction of Class II, Division 2 malocclusions using a completely customized lingual appliance and the Herbst device. J Orofac Orthop 2012; 73: 225-35.

[4] Erickson LP, Hunter WS. Class II, division 2 treatment and mandibular growth. Angle Orthod 1985; 55: 215-24.

[5] Fraenkel R, Fraenkel C. Orofacial orthopedics with the function regulator. Basel: Karger 1989.

[6] Paduano S. European board of orthodontics case report: severe skeletal discrepancy. Prog Orthod 2009; 10: 92-101.

[7] Dworkin SF, LeResche L. Research diagnostic criteria for temporomandibular disorders: review, criteria, examinations and specifications, critique. J Craniomandib Disord 1992; 6: 301-55.

[8] Iodice G, Danzi G, Cimino R, Paduano S, Michelotti A. Association between posterior crossbite, masticatory muscle pain, and disc displacement: a systematic review. Eur J Orthod 2013. [Epub ahead of print].

[9] Michelotti A, Cioffi I, Festa P, Scala G, Farella M. Oral parafunctions as risk factors for diagnostic TMD subgroups. J Oral Rehabil 2010; 37: 157-62.

[10] Paduano S, Cioffi I, Iodice G, Rapuano A, Silva R. Time efficiency of self-ligating $v s$ conventional brackets in orthodontics: effect of appliances and ligating systems. Prog Orthod 2008; 9: 74-80.

[11] Cioffi I, Piccolo A, Tagliaferri R, Paduano S, Galeotti A, Martina R. Pain perception following first orthodontic archwire placement-thermoelastic vs superelastic alloys: a randomized controlled trial. Quintessence Int 2012; 43:61-9.

[12] Martina R, Paduano S. The Translation Arch. J Clin Orthod 1997; 31: 750-3.

(C) Paduano et al.; Licensee Bentham Open.

This is an open access article licensed under the terms of the Creative Commons Attribution Non-Commercial License (http://creativecommons.org/licenses/by-nc/3.0/) which permits unrestricted, non-commercial use, distribution and reproduction in any medium, provided the work is properly cited. 